\title{
SELF EFFICACY DENGAN KUALITAS HIDUP PASIEN GAGAL GINJAL KRONIK YANG MENJALANI HEMODIALISA
}

\author{
"Welly, "Hidayataul Rahmi \\ ${ }^{1}$ Keperawatan, STIKes Alifah Padang, Jl. Khatib Sulaiman No 52 B \\ Email : wellysajjaa @gmail.com \\ ${ }^{2}$ Keperawatan, STIKes Alifah Padang, Jl. Khatib Sulaiman No 52 B \\ Email : hidayatulrahmi059@gmail.com
}

\begin{abstract}
The prevalence of Chronic Kidney Failure in Indonesia was 3.8\%, increasing from 2013 which was 2.0\%. The prevalence of chronic kidney failure in West Sumatra Province is $0.2 \%$ of the population of kidney failure patients in Indonesia, where cases of kidney disease are always increasing every year. Kidney failure can be treated one of them by undergoing hemodialysis therapy. Patients undergoing hemodialysis cause a lack of control over the activities of daily and social life, loss of freedom, early retirement, financial stress. This causes the patient's quality of life to decline because the patient not only faces health problems associated with chronic renal failure but also life-long therapy. Quality of life is very important in providing comprehensive nursing services for patients, with the hope that patients can undergo hemodialysis and can survive even with the help of a dialysis machine. The quality of a person's life can be predicted by the patient's self-efficacy, which is the belief that determines how a person thinks, motivates himself and how to finally decide to carry out a behavior to achieve the desired goal. The purpose of this study was to examine the relationship between self efficacy and the quality of life of patients with chronic kidney failure undergoing hemodialysis. This type of research is descriptive analytic. The research was conducted in the working area of Kuranji Health Center with a sample size of 33 people. It can be concluded that there is a significant relationship between self-efficacy and the quality of life of patients with chronic renal failure who undergo haemodialysis in the working area of the Kuranji Public Health Center, Padang City.
\end{abstract}

Keywords: Kidney Diseases, Hemodialysis, Self Efficacy

Prevalensi Gagal Ginjal Kronis di Indonesia sebesar 3,8\% meningkat dari tahun 2013 sebanyak 2,0\%. Prevalensi penyakit gagal ginjal kronik di Provinsi Sumatera Barat yaitu 0,2\% dari penduduk dari pasien gagal ginjal di Indonesia, yang mana kasus penyakit ginjal selalu meningkat setiap tahunnya. Penyakit gagal ginjal dapat di obati salah satunya dengan menjalani terapi hemodialisa. Pasien yang menjalani hemodialisa menyebabkan kurangnya kontrol atas aktivitas kehidupan sehari-hari dan sosial, kehilangan kebebasan, pensiun dini, tekanan keuangan. Hal itu menyebabkan kualitas hidup pasien menurun karena pasien tidak hanya menghadapi masalah kesehatan yang terkait dengan penyakit gagal ginjal kronik tetapi juga terkait dengan terapi yang berlangsung seumur hidup. Kualitas hidup menjadi sangat penting dalam pemberian layanan keperawatan yang menyeluruh bagi pasien, dengan harapan pasien dapat menjalani hemodialisa dan mampu bertahan hidup walau dengan bantuan mesin dialisa. Kualitas hidup seseorang dapat diprediksi dengan self efficacy pasien itu sendiri yang mana keyakinan yang menentukan bagaimana seseorang berfikir, memotivasi dirinya dan bagaimana akhirnya memutuskan untuk melakukan sebuah perilaku untuk mencapai tujuan yang diinginkan. Tujuan dari penelitian ini melihat Hubungan Self Efficacy Dengan Kualitas Hidup Pasien Gagal Ginjal Kronik Yang Menjalani Hemodialisa. Jenis penelitian ini deskriptif analitik. Penelitian dilaksanakan di wilayah kerja Puskesmas Kuranji dengan jumlah sampel 33 orang. Dapat disimpulkan hubungan yang bermakna antara self efficacy dengan kualitas hidup pasien gagal ginjal kronik yang menjalani haemodialisa di wilayah kerja puskesmas kuranji kota padang.

Kata Kunci : Gagal Ginjal, Hemodialisa, Self Efficacy 


\section{PENDAHULUAN}

Penyakit gagal ginjal kronik merupakan kerusakan struktur dan penurunan fungsi ginjal yang bisa berdampak pada ketidakmampuan ginjal untuk mempertahankan keseimbangan dan integritas tubuh (Suwitra, 2017). Menurut Perhimpunan Nefrologi Indonesia (Pernefri) tahun 2018 penderita ginjal yang harus cuci darah meningkat $10 \%$ setiap tahunnya yang sebagian besar penyebabnya akibat rendahnya tingkat kesadaran masyarakat dalam menjaga kesehatan ginjalnya. Hal ini menunjukan peningkatkan angka pasien yang menjalani hemodialisa tahun 2017 berjumlah 77892 orang dan tahun 2018 berjumlah 132142 orang serta tahun 2019 sekitar 499 orang per satu juta penduduk (Varwati 2020). Dalam terapi penggantian mungkin termasuk hemodialisis, dialisis peritoneal dan transplantasi ginjal. Pasien harus menjalani terapi dialisis sepanjang hidupnya (biasanya 1-3 kali seminggu) atau sampai mendapat ginjal baru melalui operasi pencangkokan ginjal (Black \& Hawks, 2014). Pasien yang menjalani hemodialisa dalam jangka waktu panjang secara tidak langsung mempengaruhi kualitas hidup seorang pasien yang meliputi kesehatan fisik, kondisi psikologis, spiritual, status sosial ekonomi dan dinamika keluarga (Smeltzer \& Bare, 2012). Pasien yang menjalani hemodialisa dalam jangka waktu panjang harus menghadapi berbagai masalah, seperti finansial, kesulitan untuk bekerja, dorongan seksual yang menurun, depresi dan ketakutan menghadapi kematian, juga gaya hidup yang harus berubah, sedikit banyak mempengaruhi semangat hidup seseorang. Pasien dengan hemodialisa semangat hidupnya mengalami penurunan karena perubahan yang harus dihadapi dan akan mempengaruhi kualitas hidup pasien gagal ginjal kronis (Parvan $\mathrm{K}$ et al, 2013). Kualitas hidup menjadi sangat penting dalam pemberian layanan keperawatan yang menyeluruh bagi pasien, dengan harapan pasien dapat menjalani hemodialisa dan mampu bertahan hidup walau dengan bantuan mesin dialisa (Khatib ST., Hemadneh MK., Hasan SA., Khazneh E., 2018).

Kualitas hidup seseorang dapat diprediksi dengan self efficacy pasien itu sendiri. Pasien gagal kronik tidak lagi percaya terhadap kemampuannya dalam menghadapi berbagai kesulitan akibat penyakit ginjal. Self efficacy didefinisikan sebagai keyakinan yang menentukan bagaimana seseorang berfikir, memotivasi dirinya dan bagaimana akhirnya memutuskan untuk melakukan sebuah perilaku untuk mencapai tujuan yang diinginkan (Luszczynska, Alexandra, 2015). Pasien yang memiliki keyakinan terhadap kemampuan mereka dalam melakukan perawatan diri akan lebih mungkin untuk melakukan tugasnya. Oleh karena itu individu dengan self efficacy yang tinggi akan lebih mampu untuk mengelola kualitas hidupnya (Reeves, Charlene J et al, 2017).

Tujuan dari penelitian untuk melihat Hubungan Self Efficacy Dengan Kualitas Hidup Pasien Gagal Ginjal Kronik Yang Menjalani Hemodialisa.

\section{METODE PENELITIAN}

Jenis penelitian yang digunakan deskriptif analitik dengan pendekatan cross sectional study, dimana pengumpulan data dilakukan dalam waktu bersamaan (Notoatmodjo, 2013). Teknik pengambilan sampel pada penelitian ini accidental sampling yaitu pengambilan sampel yang ada pada saat dilakukan penelitian. Instrumen yang digunakan dalam penelitian ini adalah kuesioner variabel self efficacy 20 Item dan kulaitas hidup pasien Gagal Ginjal 26 Item. Teknik pengumpulan data primer menggunakan kuesioner yang terdiri dari 
kuesioner pada variabel self efficacy dan kulaitas hidup, Data sekunder merupakan data yang diperoleh peneliti dari sumber yang sudah ada atau instansi yang terkait dengan

penelitian. Analisa data dengan menggunakan uji statistik Chi Square. Dalam pengolahan data dari hasil penelitian ini peneliti menggunakan komputerisasi. Untuk melihat kemaknaan 0,05 sehingga bila nilai $\mathrm{p}$ value $\leq 0,05$.

\section{HASIL DAN PEMBAHASAN}

Tabel 1

\begin{tabular}{lllc}
$\begin{array}{l}\text { Distribusi } \\
\text { berdasarkan Self }\end{array}$ & $\begin{array}{r}\text { Frekuensi } \\
\text { Ginjal } \\
\text { Hemodialisa }\end{array}$ & $\begin{array}{r}\text { Responden } \\
\text { Kronik }\end{array}$ & $\begin{array}{r}\text { Yang } \\
\text { Hen Gagal } \\
\text { Menjalani }\end{array}$ \\
\hline No & $\begin{array}{l}\text { Self } \\
\text { Efficacy }\end{array}$ & $\boldsymbol{f}$ & $\%$ \\
\hline 1 & Tinggi & 23 & 69,6 \\
\hline 2 & Rendah & 10 & 30,4 \\
\hline Jumlah & & $\mathbf{3 3}$ & 100,0 \\
\hline
\end{tabular}

Berdasarkan tabel 1 dapat dilihat bahwa dari 33 orang responden terdapat lebih dari separuh $(69,6 \%)$ responden dengan Self Efficacy tinggi

\section{Tabel 2}

Distribusi Frekuensi Responden berdasarkan Kualitas Hidup Pasien Gagal Ginjal Kronik Yang Menjalani Hemodialisa

\begin{tabular}{llll}
\hline No & $\begin{array}{l}\text { Kualitas } \\
\text { Hidup }\end{array}$ & $\boldsymbol{f}$ & $\mathbf{\%}$ \\
\hline 1 & Baik & 21 & 63,6 \\
\hline 2 & Buruk & 12 & 36,3 \\
\hline Jumlah & & $\mathbf{3 3}$ & 100,0 \\
\hline
\end{tabular}

Berdasarkan tabel 2 dapat dilihat bahwa dari 33 orang responden terdapat lebih dari separuh $(63,6 \%)$ responden memiliki kualitas hidup yang baik
Tabel 3

Hubungan Self Efficacy Dengan Kualitas Hidup Pasien Gagal Ginjal Kronik Yang Menjalani Hemodialisa

\begin{tabular}{|c|c|c|c|c|c|c|c|}
\hline \multirow{3}{*}{$\begin{array}{c}\text { Self } \\
\text { Efficacy }\end{array}$} & \multicolumn{4}{|c|}{ Kualitas Hidup } & \multirow{2}{*}{\multicolumn{2}{|c|}{ Total }} & \multirow{3}{*}{$\begin{array}{c}\mathbf{P} \\
\text { value }\end{array}$} \\
\hline & \multicolumn{2}{|c|}{ Baik } & \multicolumn{2}{|c|}{ Buruk } & & & \\
\hline & $f$ & $\%$ & $f$ & $\%$ & $f$ & $\%$ & \\
\hline Baik & 13 & $\begin{array}{c}56, \\
5\end{array}$ & 10 & 43,4 & 23 & $\begin{array}{c}100 \\
0\end{array}$ & \\
\hline Buruk & 5 & $\begin{array}{c}50, \\
0\end{array}$ & 5 & 50,0 & 10 & $\begin{array}{c}100 \\
0\end{array}$ & 0,000 \\
\hline Total & 18 & $\begin{array}{c}54, \\
5\end{array}$ & 15 & 45,4 & 33 & $\begin{array}{c}100, \\
0\end{array}$ & \\
\hline
\end{tabular}

Berdasarkan tabel 3 dapat dilihat bahwa proporsi responden dengan Self Efficacy baik memiliki kualitas hidup yang baik yaitu $56,5 \%$ lebih tinggi daripada responden dengan Self Efficacy baik dengan kualitas hidup buruk yaitu $45,4 \%$. Hasil uji chi-square didapatkan nilai $\mathrm{p}=0,000 \quad(\mathrm{p}<0,05)$ artinya terdapat hubungan yang bermakna antara Self Efficacy dengan kualitas hidup pasien GGK yang menjalani Haemodialisa.

\section{Pembahasan}

a. Distribusi Frekuensi Self Efficacy

Berdasarkan Hasil penelitian menunjukkan bahwa dari 33 orang responden terdapat lebih dari separuh $(69,6 \%)$ responden dengan Self Efficacy tinggi. Hasil penelitian ini sejalan dengan penelitian oleh Wa Ode (2020) didapatkan hasil lebih dari separoh $(66,7 \%)$ memiliki efikasi diri tinggi dan hanya $(33,3 \%)$ pasien yang memiliki efikasi diri rendah. Self Efficacy erat kaitannya dengan keinginan dan 
keyakinan individu untuk berperilaku sehat, seseorang yang memiliki keyakinan bahwa mereka dapat melakukan perilaku yang dapat menunjang kesehatan dan berperilaku sehat maka akan cenderung memiliki keinginan untuk mencoba dan berubah (Reeves, Charlene J et al, 2017).

Self Efficacy memiliki peran dalam inisiasi dan pemeliharaan perilaku kesehatan, sehingga diyakini bahwa peningkatan self efficacy pada perilaku kesehatan akan mengakibatkan perbaikan kesehatan dan meningkatkan perilaku serta kualitas hidup, sehingga kualitas hidup seseorang dapat diprediksi dengan self efficacy pasien itu sendiri (Luszczynska, Alexandra, 2015). Tingginya self efficacy responden dalam penelitian ini disebabkan karena responden masih memiliki tujuan hidup, responden percaya dan yakin kalau mereka mampu menjalani kehidupan seperti biasa tanpa ada rasa malu dan minder meskipun harus menjalani haemodialisa. Sebaliknya, responden yang memiliki self efficacy yang rendah disebabkan karena responden tidak percaya diri dan kecewa dengan dirinya serta takut tidak bisa melalui hari-harinya dengan kondisinya yang harus menjalani hemodialisa.

\section{b. Distribusi Frekuensi Kualitas Hidup}

Berdasarkan tabel 2 dapat dilihat bahwa dari 33 orang responden terdapat lebih dari separuh $(63,6 \%)$ responden memiliki kualitas hidup yang baik. Hasil penelitian ini sejalan dengan penelitian yang dilakukan oleh Muhammad Fuat (2016) mengenai kualitas hidup pasien gagal ginjal yang menjalani haemodialisa di Jakarta, didapatkan hasil sebagian besar responden memiliki kualitas hidup yang rendah, yaitu 19 orang $(54,30 \%)$ pada kelompok single-use dan sebanyak 23 orang $(65,75 \%)$ pada kelompok re-use. Penelitian ini juga sejalan dengan penelitian Wa Ode (2020) bahwa dari hasil penelitian terhadap 30 pasien, separoh pasien $(50 \%)$ memiliki kualitas hidup rendah.

Pasien gagal ginjal kronis yang menjalani hemodialisa mengalami penurunan semangat hidup karena perubahan dan rutinitas pengobatan yang harus dihadapi dan dijalani secara berkesinambungan dan akan mempengaruhi kualitas hidup pasien gagal ginjal kronis. Tindakan hemodialisa secara tidak langsung mempengaruhi kualitas hidup seorang pasien yang meliputi kesehatan fisik, kondisi psikologis, spiritual, status sosial ekonomi dan dinamika keluarga (Smeltzer \& Bare, 2012)

Menurut asumsi peneliti baiknya kualitas hidup responden yang menjalani haemodialisa dapat disebabkan karena pemahaman responden tentang gagal ginjal dan pentingnya hemodialisa sangat bagus. Hal tersebut berhubungan dengan kualitas hidup penderita terutama kualitas secara fisiologis. Selain itu responden sudah berada pada tahap fase menerima sehingga responden menjalani hari-hari dengan iklas meskipun harus menjalani haemodialisa. Selain itu responden dapat merasakan kondisi fisiknya semakin membaik setelah menjalni haemodialisa.

\section{c. Hubungan Self Efficacy Dengan Kualitas Hidup Pasien Gagal Ginjal Kronik Yang Menjalani Hemodialisa}

Berdasarkan tabel 3 dapat dilihat bahwa proporsi responden dengan Self Efficacy baik memiliki kualitas hidup yang baik yaitu 56,5\% lebih tinggi daripada responden dengan Self Efficacy baik dengan kualitas hidup buruk yaitu $45,4 \%$. Hasil uji chi-square didapatkan nilai $\mathrm{p}=0,000 \quad(\mathrm{p}<0,05) \quad$ artinya terdapat 
hubungan yang bermakna antara Self Efficacy dengan kualitas hidup pasien GGK yang menjalani hemodialisa.

Penelitian ini sejalan dengan penelitian Hakim (2018) dari Hasil uji chi square diperoleh nilai $\rho$-value 0,001 dengan artian terdapat hubungan yang signifikan antara Self Efficacy dengan kualitas hidup pasien gagal ginjal kronik yang menjalani hemodialisa di RSUD Dr. Moewardi, dimana nilai rhitung 0,765 yang berarti memiliki korelasi tinggi yang dapat disimpulkan pasien gagal ginjal kronik yang memiliki Self Efficacy tinggi memiliki kualitas hidup yang baik dan sebaliknya pasien dengan Self Efficacy rendah memiliki kualitas hidup yang buruk.

Hasil penelitian ini juga sejalan dengan hasil penelitian Ega (2017) yaitu adanya hubungan bermakna antara Self Efficacy dengan kualitas hidup pasien gagal ginjal kronis yang menjalani hemodialysis dengan nlai $\rho$-value $=0,000$ dengan arah hubungan positif dan kekuatan korelasi sedang $(\mathrm{r}=0,466)$, dapat disimpulkan bahwa semakin baik Self Efficacy maka kualitas hidup juga semkain baik.

Self efficacy merupakan fasilitator perubahan fungsi fisiologis dan perubahan dalam kualitas hidup pasien. Pasien yang menjalani haemodialisa yang memiliki tingkat self efficacy tinggi maka dapat melakukan aktifitas fisik dan fungsi psikososial yang lebih tinggi juga dibandingkan dengan yang mempunyai self efficacy lebih rendah (Caroline, 2014). Self-efficacy juga berkaitan dengan kemampuan seseong dalam berperilaku sehat, jika seseorang tidak yakin dalam melakukan perilaku yang dapat menunjang kesehatan nya maka seseorag itu akan akan cenderung untuk tidak memiliki keinginan untuk mencoba sesuatu yang baru sehingga perpengaruh terhadap kualitas hidup (Fathia Ahmed Mersal, 2014).

Membangun kepercayaan diri pasien akan kemampuannya (self efficacy) dalam mencapai sesuatu merupakan jalan yang positif dalam mencapai kualitas hidup yang lebih baik. Self efficacy mempunyai hubungan yang positif dengan perilaku perawatan diri yang pada akhirnya akan meningkatkan kualitas hidup. Manajemen fisik dan psikologis dalam menurunkan gejala fisik dan peningkatan kepatuhan terhadap pengobatan serta perubahan perilaku dalam promosi kesehatan sangat erat kaitannnya dengan peningkatan Self efficacy pada pasien gagal ginjal kronis yang menjalani haemodialisa.

Kualitas hidup merupakan satu komponen utama yang bersifat subyektif untuk kesejahteraan hidup manusia. Pasien gagal ginjal konis yang menjalani hemodialisis harus mampu melakukan manajemen diri yang baik dan efektif, baik dalam manajemen fisik, psikologis maupun manajemen social (Leila, 2014).

\section{SIMPULAN}

Terdapat $(69,6 \%)$ responden dengan Self Efficacy tinggi, Terdapat lebih dari separuh $(63,6 \%)$ responden memiliki kualitas hidup yang baik, dan Terdapat hubungan yang bermakna antara Self Efficacy dengan kualitas hidup pasien Gagal Ginjal Kronik yang menjalani Haemodialisa di Wilayah Kerja Puskesmas Kuranji Kota Padang.

\section{DAFTAR PUSTAKA}

Alwisol, 2018. Psikologi Kepribadian, Malang. UMM Pres 
Ariani, 2011. Hubungan antara Motivasi dengan Self efficacy Pasien DM Tipe 2 dalam Konteks Asuhan Keperawatan di RSUP. H. Adam Malik Medan. (Tesis). Depok: Universitas Indonesia

Ayoub AMA. Quality of Life Among Dialysis Patients in United Arab Emirates. 2012.

Bandura, 2011. Self Efficacy: The Exercise of Control. USA: W.H. Freemen and Company

Black, J. M., \& Hawks, J. H. (2014). Keperawatan Medikal Bedah. In Buku 2 (pp. 355-400).

Firmansyah, 2015. Kecemasan mahasiswa dalam menyelsaikan tugas akhir studi (studi kasus fakultas dakwah dan komunikasi). Skripsi. IAIN Walisongo Semarang.

Friedman, M.M Bowden, V R. \& Jones, E. . (2013). Buku Ajar Keperawatan Keluarga Riset, Teori dan Praktek. Jakarta: EGC.

Khatib ST., Hemadneh MK., Hasan SA., Khazneh E., Z. S. (n.d.). Quality of life in hemodialysis diabetic patients: A multicenter cross-sectional study from Palestine.

Luszczynska, Alexandra. General selfefficacy in various domains of human functioning : Evidence from five countries. International Journal of Psychology. 2015; 40 (2): 80-89.

Mubarak, 2012. Ilmu Kesehatan Masyarakat Konsep dan Aplikasi dalam Kebidanan. Jakarta: SalembaMedika.
Moreno F., Sanz-Guajardo D., Lopez-Gomez JM., Jofre R., Valderrabano F. Increasing the hematocrit has a beneficial effect on quality of life and is safe in selected hemodialysis patients. J Am Soc Nephrol. 2000;11(2):335342.

Notoatmodjo, 2015. Metodologi Penelitian Kesehatan. Jakarta : Rineka Cipta.

Novitasari, 2018. Hubungan Dukungan Keluarga Dengan Self efficacy Pasien Gagal Ginjal Kronik Yang Menjalani Hemodialisa di RSUD Kabupaten Semarang

Parvan K., Lakdizaji S., Roshangar F., Mostofi M. Quality of sleep and its relationship to quality of life in hemodialysis patients. $J$ caring Sci. 2013;2(4):295-304.

Reeves, Charlene J, dkk. Keperawatan medikal bedah . Ed 1. Jakarta : Salemba Medika. 2017.

Taylor, 2012. Health Psychology. Eighth Edition. New York: Mc Graw Hill.

Tsay, Shiow-Luan \& Healstead, Marilyn. Self-care self-efficacy, depression, and quality of life among patients receiving hemodialysis in Taiwan. International Journal of Nursing Studies. 2012; 39(3): 24551.

Varwati, 2020. Penderita Sakit Ginjal di Indonesia Meningkat Dua Kali Lipat Sejak 2013, Jakarta.

Valensi, P., Girod, I., Baron, F., MoreauDefarges, T., \& Guillon, P. (2005). Quality of life and clinical correlates in patients with diabetic foot ulcers. Diabetes \& Metabolism, 31(3), 263271. https://doi.org/10.1016/S12623636(07)70193-3 
Van KN., Duangpaeng S., Deenan A., Bonner A. Examining the health-related quality oflife of people $\mathrm{v}^{\wedge}$ ith end-stage kidney disease living in Hanoi, Vietnam. Ren Soc Australas J. 2012;8(3):140-145.

Videbeck, S. L. (2011). Psychiatric-mental health

nursing.https://doi.org/10.1017/CBO97 81107415324.004 